\title{
论城市园林建设中花卉的栽植及应用
}

\author{
王敏 \\ 黑龙江齐齐哈尔市园林管理处 \\ DOI:10.32629/as.v2i4.1631
}

[摘 要] 近年来随着安庆经济的飞速发展和城市建设水平不断提高, 对于绿化工程的美化效果也要求更加严格, 因此花异也 越来越多地应用在绿化工程项目中。花卉的栽植及后期养护是绿化工程中的难点,如操作失误,会造成较大的经济损失。为更 好地满足人们对城市园林建设提出的基本要求,要积极栽培适宜的花卉, 大力推进园林绿化建设,利用花卉栽植来美化城市环 境,提升园林整体形象。基于此,文章就城市园林建设中花卉的栽植及应用进行了简单研究。

[关键词]城市园林建设; 花卉的栽植; 运用

花卉栽培技术主要包括草本花卉的概念及分类、草本花 卉设施栽培的设备与应用、花卉应用、花卉与环境的关系、 草本花卉的繁殖以及工厂育苗、花卉栽培技术、花卉常见病 虫害及其防治等内容。花卉的种类很多, 与其生长发育相适 应土壤的特性也有很大的差别。一般而言, 多数花卉要求土 壤富含腐殖质, 土壤疏松肥沃, 排水良好, 透气性强。绝大多 数陆地花卉要求土壤的 $\mathrm{pH}$ 值在 7.0 左右, 而温室花卉则要求 酸性土壤。

\section{1 花卉在城市园林绿化中的主要作用}

城市园林建设中, 花卉起到了非常重要的作用, 可以改 善园林自然条件, 美化园林环境, 同时还可以愉悦市民心情, 从一定程度上说, 园林中的花卉具有一定的振奋人心的良好 作用。花卉种类较多, 不同花卉品种有属于自己的生活习性。 从观赏性来分有观花类花卉、观果类花卉、观叶类花卉等, 不同花卉形态各异, 因此出现了千差万别的生态习性。从使 用性来分, 花卉可分为人行道、大型广场花坛、花镜、造景 使用,也可用于公园、广场大量地栽使用。

\section{2 花卉造景的原则}

2.1 深入了解立地条件和花卉的特性

对花卉栽植前, 应该掌握当地的土壤状况, 阳光的照射 时间以及气温等条件, 还应该对花卉本身的生长习性进行掌 握, 进行合理配置, 避免造成因为花卉的习性不了解, 造成人 力、物力以及财力的浪费。

\section{2 根据绿地不同性质和功能进行配置}

要根据绿地不同的布置类型, 选择不同的花卉, 比如, 在 公园应该选择一些观赏性较高的花卉, 在工厂则要选择一些 抗污吸尘的品种, 在公园以及公路上要选择颜色亮丽的品种。

2. 3花卉的栽植应与景观建设匹配

花卉的栽植应该与当地的呼应, 形成一个和谐统一、相 得益彰的效果, 要满足人们对热爱自然的需求, 让人们在工 作生活之余可以随时观察到自然之美。

\section{3 花卉植物设计的要点}

3.1花卉设计的科学性

先对花卉寿命、种类进行充分了解, 因地制宜地进行花
卉类型的选择, 才能实现设计的合理性。其次, 对花卉种植季 节特性进行掌握。由于花卉具有不同生命周期、生长发育周 期, 具有较为显著的季节性, 进而呈现出不一样的观赏特点。 最后, 因生长期的改变, 花卉植物叶、花及果期也不尽相同, 进而其具有不同的观赏性。通过花卉的观赏时间进行花卉设 计时间层次的合理规划, 只有这样才能确保一年四季具有不 同的景观。

\section{2 花卉设计的艺术性}

园林构成形式要素的和谐、要素和要素间的和谐、要素 组合整体空间布局的和谐为园林景观设计和谐统一的主要 内容。园林花卉种植设计应充分融入园林整体景观设计, 对 整体园林设计相适应, 才能将园林设计美感充足展现出来, 才能将花卉景观的作用充分发挥出来。我国古典画作遵循 “丈山尺树, 寸马分人” 的美学比例, 园林设计也应具有美学 价值。在种植设计花卉景观时, 应重视各个要素之间的协调 性, 确保其配置符合审美观点, 如园林具有较大的空间时, 选 用的植物应具有高大、量多的特点, 只有这样才能达到协调 景观的作用。

\section{4 城市园林建设中花卉的栽植}

4. 1 草本花卉的栽植技术

整地是园林花卉栽植的首要工作。冬季结冻之前进行深 翻整地, 将翻地深度控制在 $20 \sim 30 \mathrm{~cm}$ 之间; 合理地选择花卉 品种, 及时清理换土, 更换干净土壤; 做好间苗工作, 分苗时 确保温度和水分, 防止对幼苗生长造成严重威胁; 移栽一次 性到位, 采用带土坨移栽, 移栽后及时浇水, 提高园林花卉的 成活率; 定植之后需要进行两次灌溉, 常规的灌溉方式有滴 灌、喷灌等形式。然后进行松土追肥。春、夏季适当增加花 卉的灌溉量, 秋季适当减少灌溉量, 应结合季节特点来进行 合理灌溉; 根据不同花卉品种有针对性施肥, 以氮肥为主, 保证花卉能够正常开花; 花卉生长的中后期控制好氮肥用量, 同时增加磷肥和钾肥的使用量。园林建设中, 对不同植物、 不同色彩进行合理搭配, 成片栽植, 将基本色彩按照不同比 例混合成多彩的园林色调。根据色彩变化使不同植物的不同 色彩形成色环图。将观叶花卉与观花植物合理搭配, 注意季 
节变化, 形成不同季相的园林景观。在园林走廊运用适量木 本花卉, 如紫叶李、金丝垂柳、榆叶梅、五角枫、万寿菊、 孔雀草等, 使得游人在行走时感觉赏心悦目, 愉悦心情。

\section{2 观赏类花卉的运用}

城市园林建设中有水生花卉、一年生花卉、木本花卉、 观赏类花卉、球根花卉等多种品种的花卉, 应选择栽植不同 季相的木本花卉, 如春季有紫荆、白兰花、含笑、迎春、红 叶李、石楠等, 夏季有丁香、紫微、海棠, 秋季有多头菊、国 庆菊, 冬季有甘蓝, 使得园林内四季有花。根据地区实际环境 特点来选用适宜的花卉种类, 真正做到适地适树。考虑不同 植物之间的影响, 及时将乔、灌、多层次相结合, 以此来减弱 不同植物根系的竞争。草本类花卉自身具有很强的适应性和 耐寒性, 要想保证生长周期足够长, 园林建设中可及时栽植 金光菊、桔梗、药药等花卉, 使其发挥出观赏效果。将观赏 类花卉 (翠菊、薰衣草) 等运用在花坛布置中, 烘托气氛, 有效 丰富花坛。运用观赏类花卉, 合理搭配花卉色彩, 构建苗圃, 更好地运用花卉资源, 及时形成丰富的园林景观色彩, 并发 挥出良好的绿化效果。

\section{5 园林花卉的养护与管理}

5. 1 提高种子培育技术

\section{1. 1 土壤能为花卉种子培育打好基础}

土壤的虚实度、干湿度、细碎度都会影响到种子的发芽 情况。掩埋在种子上的土壤虚碎有利于种子的破土, 而盖上 的厚度取决与种子的大小, 越大的种子盖土的厚度也要随之 增加, 相反就减少; 而细粒的种子并不需要土壤的掩盖, 因为 细粒的种子不容易顶土而出。过干的土壤会影响种子的发芽 破土, 手捏土壤能感受到一点湿迹, 那对种子的生长最有利, 所以保持土壤的潮湿度很重要。

\section{1.2 提高种子发芽率}

强烈的日照对种子发有芽并没有起到特别的好处, 反而 适度的遮光对种子发芽有帮助。而对于极少的植物来说种子 萌发需要黑暗, 那么就相反的减少日照为宜。

\section{1.3 提高种子发芽后存活率}

花卉的成长速度取决于环境的温度, 而在种子发芽生长 的阶段温度可以保证其存活率。为了种子发芽后能健康成长, 发芽阶段的温度设置要略低于其原本需要的温度。所以环境 温度不仅能影响花卉的生长速度, 还能决定它的存活。种子 的培育技术提升可以增加园林花卉种子的多样性并提高出 口贸易额。为了更好的满足现代人对园林花卉的应用需求以
及通过出口获得更大的城市经济效益, 必须使花卉在保持多 样性品种的条件下得到更好的养护与管理。

\section{2 花卉病害防治}

保持园林内花卉四周环境优良, 减少病害的出现, 保证 花卉的叶、茎、根等部位无损伤、无破皮, 有效预防花卉病 害。不定时到园林巡视, 及时杀死害虫和病菌。严格执行消 毒制度, 早春和花芽发芽前, 对有病害的花卉喷 $1 \sim 3$ 次波尔 多液, 防治枯、防病虫害, 时刻观察花卉的叶片和长势, 将多 菌灵波尔多液喷酒在露菌病草本花卉叶片的白斑部位, 为花 卉生长提供足够的光照, 加强通风, 科学防治。积极了解花卉 病害识别知识, 常见的花卉病害分为寄生性病害和生理性病 害这两大类, 及时改善气候和土壤条件, 避免强光直射, 不定 时进行巡视, 认真观察花卉水分以及生长状况, 便于第一时 间补充营养元素, 最大程度减少病害发生。

\section{3注意防寒}

有些花卉在冬季寒冷季节容易冻伤或是冻死, 所以做好 防寒工作对保护花卉来说至关重要。搭棚进行防寒或是将其 转入暖室都是最为普遍的方法。花卉的高效培养以及维护可 以提升园林花卉的多样性, 从而减少对发达国家园林花卉的 进口率并解决贸易逆差的问题。

\section{6 结语}

综上所述, 花卉有非常重要的作用, 可以改善园林自然条 件, 美化园林环境, 因此要重视花卉栽植和养护工作。随着科 学技术的不断发展, 花卉栽培应用与养护技术也得到了很多 改善和拓展, 通过人们的努力, 将绿色植物与环境更加有机地 结合起来, 为人们美好的生活增添了色彩。花卉是整个园林绿 化工程中的重要组成部分, 园林绿化过程中对花卉的栽培和 养护, 将直接关系到整个园林绿化的效果, 因此, 加强对园林 花卉栽培和养护的探讨, 有助于园林工程的健康发展。

\section{[参考文献]}

[1]孙银生.园林花斗栽培与管理技术问题的探讨 [J]. 现 代园艺,2019(11):72-73.

[2]叶平.浅谈园林花斗栽培与管理的若干技术问题 [J]. 农村经济与科技,2019(10):27。

[3]高天宏.园林绿化中花卉栽培技术与养护管理措施 [J].乡村科技,2018(30):62-63.

[4]吴强.园林花斗栽培与管理技术问题的探讨 [J]. 现代 园艺,2018(18):46 